\title{
Schools of the Future: Analysing the Present
}

\author{
Elizabeth Braithwaite
}

A suburban Melbourne secondary college' offers prospective students the opportunity to 'develop into responsible citizens' and in so doing underscores one of the most significant aspects of the Western education system: that of teaching young people to fit into society. A second form of socialisation for many young people (Stephens, 1992a, p.8) is an activity which tends to occupy a sizeable part of those very school days; namely, reading fiction designed for the adolescent age group. And although in the classroom students and teachers have the opportunity to critique this second form of socialisation, many authors of Young Adult fiction are positioning their readers to explore the first as well. For since both schooling and reading are significant means by which young people are taught to fit into the society in which they live, exploring the construction of schooling in Young Adult texts becomes a multi-layered experience through which a reader may come to reflect more closely about his/her own society and its future.

Constructions of schools in futuristic texts make a particularly significant field of study because they invite the reader not just to experience a theoretical futuristic society but also to look at how people are trained to fit into that society - which by implication explains how the society is maintained. And in a study of futuristic texts. the text's past becomes the reader's present, and the future therefore a place over which the implied reader has control in a way that the protagonists do not (Stephens, $1992 \mathrm{~b} \mathrm{p.} \mathrm{126).} \mathrm{In} \mathrm{other} \mathrm{words,} \mathrm{if} \mathrm{the} \mathrm{reader} \mathrm{does} \mathrm{not} \mathrm{like}$ the way the world has become in the text, the onus is on that reader to do something about preventing the horrors of the text from becoming reality.

Through an examination of four novels-Robert Westall's Futuretrack 5, Lois Lowry's The Giver, Robert Swindells' Daz 4 Zoe and Jill Dobson's The Inheritors - this paper will focus on a number of aspects of schooling in futuristic texts for young adults. Even though the texts were all published between 1983 and 1993 these novels still provide a variety of potentially prophetic models for the reader since the precise dates given in three of the texts have not yet come to pass, and the technological advances in the fourth are still theory rather than reality. ${ }^{2}$ At the same time the texts also comment on the concerns of a time far back enough for a reader to view it with some distance. In this way the reader is invited to think about how much progress has been made towards avoiding the horrific futures presented by the texts and whether the fears of the decade which produced the novels have disappeared or changed.

Whilst the four novels differ from each other in many ways, several consistent themes emerge: the importance of young people finding what truth means for them; how language can be both a powerful tool of communication and at the same time the means of hiding what the text constructs as reality; and also how fitting into society is not necessarily always a positive aim for a young person. These concepts will be examined through four sections in the paper: the function of schools in futuristic societies, the importance of school as 'place', representations of teachers in futuristic texts, and how schooling in futuristic texts comments on the reader's present.

1. Going to school or getting brainwashed? The function of schools in futuristic societies

In various ways the schools in the four texts all take to extremes traits that can already be observed in the reader's society. In summary, these traits are: an increasing stratification of society (Manne 2000, p.15, McGregor 1995, p.33), a reluctance to embrace aspects of the past which may lead to personal development (Black 1999. p.13), a reliance on science and/or technology at the expense of personal relationships (McGregor 1995, p.33, Merson 1999, p.73), and fear (McGregor 1995, p.33). ${ }^{3}$

All four texts use aspects of schooling with which most readers in the early twenty-first century would be familiar: the notion of school as a place in which students are trained to fit into society; the idea that the school experience is able to impart something which the prevailing culture believes would be good for the student; and the concepts of teacher and student and the implied status difference between them. These similarities between the schools in futuristic texts and the reader's probable own experience invites the reader to ask how such a familiar situation can become so negative, and what can be done to stop this happening.

A place of 'emotional safety' is how social commentator Hugh Mackay (2001, p.7) describes the late twentieth/

Copyright of Full Text rests with the original copyright owner and, except as permitted under the Copyright Act 1968, copying this copyright material is prohibited without the permission of the owner or its exclusive licensee or agent or by way of a licence from Copyright Agency Limited. For information about such licences contact Copyright Agency Limited on (02) $93947600(\mathrm{ph})$ or (02) 93947601 (fax) 
early twenty-first century school experience for many people. However, the idea that school might actually be of use to students as individuals is only rarely, if ever, discussed in any of the four texts and the implied fear is that schools will become places which serve a dysfunctional society, not meeting the needs of individual students. In The Giver (1993, pp.3-4), for example, school is presented as a place in which one learns to talk 'correctly' and in which a child may be observed so that the Elders may decide what task they think the child should carry out as an adult (p.15).

In Swindells' Daz 4 Zoe (1990), formal education has a different function for the Subbies than it does for the Chippies, with significant implications of class. For Zoe and those like her, school is a place where they must go to learn the skills necessary for the types of employment which will enable them to maintain their Subby (suburbanite) standard of living (p.5). Much as Zoe dislikes school, she is determined not to be expelled, but it is implied that this is chiefly because she wants to maintain her Subby standard of living (p.55).

For the lower class Chippies, however, school is a means by which they have an extremely remote chance of gaining entrance to a Subby school and ultimately suburbia, which is assumed by at least those who have designed the education system to be desirable (p.14).

Nonetheless, many of the Chippies actually want to come to school (p. 145). Exactly why this is the case is not made clear, but one reason might be relief of boredom (p.36) and another may be a forlorn hope of escaping from poverty into what they have been taught is a better life (p.14) - the stratification of which Manne and McGregor write has become an inescapable reality in Daz and Zoe's world. The reader has been positioned to suspect this through the 'True Story' before the text proper begins, as well as by the authorial invitation to make sure that the rest of the text does not actually become reality for the reader (p.2).

The chief purpose of 'education' in The Inheritors is to indoctrinate the young person into supporting the Ideology on which the Dome is based, and without which it cannot function (p.157). For much of the novel it seems also that the only choice for the characters is life in the Dome or certain death outside (pp. 3-4, for example), a situation resulting from a nuclear holocaust of 2016 (p.2).

The main function of school in Futuretrack 5 appears to be enabling society to decide what to do with its young people (pp.16, 17) and Kitson - the chief protagonist himself comes to the conclusion that school has largely been a means by which he will be classified as an Est (pp.16-17). His prediction about himself proves to be wrong, however (p.37). Equally, the reader is positioned to see that education as a means of indoctrination or as a means of deciding what a young person 'should' (in terms of society in the text) be doing as an adult tends not to work to the young person's advantage. Kit, for example, realizes that to stay in the Centre to which he has been assigned would mean that he would end up 'like a white hen ... cramped in its own cage' (p.63).

Apart from the occasional useful tidbit of information, by and large schooling in futuristic texts is therefore presented as either damaging or irrelevant to its students. The young female pickpocket in Futuretrack 5 further demonstrates this, for despite her ability to quote reams of Virgil with total accuracy, she has been pushed into the world of the Unnems and lives by stealing (pp.69-70). If anything, school seems to have taught her only superfluities for the life in which she finds herself, in the same way that the knots which Kit and his classmates have learned to tie are more for the prestige of the school than they are for any future use for the student (p.14).

Several of the writers are particularly careful to draw a distinction between amassing facts and having true wisdom, thus inviting the reader to do the same. This is exemplified in the passage from Lowry's text in which Jonas eagerly tells The Giver that his Instructors have taught him about how the brain works. The Giver responds by simply saying, 'They know nothing' (p. 105).

This differentiation between knowledge and wisdom continues as The Giver explains that exacting scientific training is meaningless without memories (p.105). These types of memories are presented as being similar to Jung's collective unconscious ${ }^{4}$ and The Giver explains that through familiarity with and understanding of archetypal experiences (as opposed to indoctrination), people become wise and can form a future (p.79). 
However, The Giver makes it clear that it is only through engagement with those archetypal experiences - such as those which he enables Jonas to encounter (pp. 1 19-20 for example) that a person can grow, not merely by reading about them at school.

Nonetheless, a resistant reader might wonder if this is merely another form of indoctrination. However, because The Giver's teaching helps Jonas escape from the community - which the reader has been positioned to oppose - towards one in which positive aspects of the reader's world are highlighted ${ }^{\text {s }}$, it is hard not to align with The Giver.

Lowry also makes it doubly clear that for Jonas, real education has very little to do with school. When school is mentioned it is usually as a means of illustrating something else, such as the depth of Jonas' feelings (p.4) which are themselves at odds with the ethos of his society (p.153). That Jonas and his friends continue to study the same subjects as each other, despite the profound differences between the careers for which they have been assigned and the role to which Jonas has been 'selected', also emphasises the gulf between Jonas and his friends and the irrelevance of their education to what the text constructs as personal growth (pp.61, 89). The implied fear is that schools will become places that are so wrapped up in maintaining the social status quo that they actively discourage any enquiry on the part of the student.

Swindells, by contrast, has a curiously ambivalent attitude in his text towards Subby schooling. He has the Chippy Daz acknowledge that Mr James has taught them the story of the Minotaur (by which means Daz finds Zoe [p.56]), but does not explain how Zoe found out about Galileo (p.55). The source could perhaps have been Zoe's grandmother, although given her grandmother's importance as a balance to the prevailing views in the society (p.54) this source would surely have been acknowledged, or Zoe could perhaps have found it out for herself, or perhaps even a parent might have told her, but it is equally likely that she learnt it at school.

If this is the case, then Zoe is either displaying a particularly mature attitude in that she seems to be able to dissociate what she has learned from where she has learnt it - or Swindells is trying to have a foot in both camps in his construction of Subby schools. For Zoe to concede that she learnt something useful at school could come across as mitigating the construction of Subby-dom as stifling, which dominates much of the text (pp.19,84 for example).

For all the authorities' attempts to indoctrinate or make decisions on behalf of the young person in the text, in all four novels the reader is positioned to see the flip side of what is going on. This encourages the reader to align with the subtext - namely to oppose the prevailing social order in the text. In Futuretrack 5 , for example, the reader can see the instability and fear which lie beneath the carefully constructed society, and which the Headmaster demonstrates when his mask is pulled aside (p.30). In $\mathrm{Daz} 4$ Zoe the reader is made aware of the inequality of the system, and how thinking only of oneself, as Lieutenant Pohlman recommends, does not guarantee happiness (p.84). For all the security of 'community' in The Giver, abrogating choice and expecting someone else to carry pain on behalf of other people actually limits both the individual and the society (pp.98, 99, 113). And in The Inheritors Dobson suggests that freedom from fear and starvation at the expense of hope are less appealing than they might first seem to be (pp.133, 142).

\section{2. 'Well its som wear to go innit" : The importance of school as 'place'}

In some of the texts 'school' is a separate area from the rest of the neighbourhood in which the protagonist lives, and in other texts the physical location and features of the school are scarcely mentioned. The difference between these two scenarios is often significant in terms of the ideologies of the various texts.

In Dobson's novel, the City is divided into areas which provide specific functions (pp.62, 122). The City Education Block (p.62) differs from the others only inasmuch as the various zones have their own uses, reflecting the implied belief in the Ideology that all socially sanctioned tasks are of equal value (pp.4-5).

In Lowry's text, 'school' is both a time and a place which is structured into the young person's life. Jonas includes it in the list of places during which he has seen the Elders watching him (p.15) - as if it were no different from anything else or anywhere else he goes at this early stage. 
Whether school is a physically separate place from the rest of the community is thereby constructed as irrelevant, and school both as a time and place becomes less important as the young people commence their training for their adult careers (pp.18, 90). This seemingly inevitable merging of one part of life into another, both in a physical and temporal sense, reflects the dislike the community has of making choices which involve any measure of risk (p.98).

By contrast, in Futuretrack 5, the physical nature of the school is important. Several times even on the first page Westall sets up oppositions as if encouraging the reader to see the contrived luxurious surroundings of the school as undesirable: Kitson's own privileges in contrast to the Chinese mess waiter who is treated as scarcely human (and just how badly these mess-boys are treated is revealed tragically only two pages later), the beautiful view and polished parquet in contrast to the distant robot cranes, and thirty years ago compared to the 'now' of the text ... (p.7).

Artifice also comes across in Westall's text as one of the most significant aspects of the school: simply by virtue of its location, for example, the school has been given a naval flavour and its students forced to learn to do things that are useless because no one who is human does those things anymore (p.14). The fact that the school is on an island (p.70) reinforces its isolation from the rest of the world, both in a physical sense and in the irrelevance of what it teaches. Through these techniques the reader is positioned to read between the carefully constructed lines of the school to see something unknown and frightening beneath. Because it dominates so much of the early part of the novel, the obvious constructedness of the school also alerts the reader to artificiality in the wider world within the text. Similarly, the clear differentiation between student and mess boys, prefects and 'kids', the parents of the Sixth and other parents (pp.7, 11, 14) prefigure the strata which Kitson later encounters (pp.37, 103, 205).

The physical nature of the school and its separateness from other buildings in Daz and Zoe's neighbourhoods are also significant in terms of the text's ethos. The gulf between Zoe and her parents is underscored by the physical act of going to school, since it means that Zoe can get away from them (p.93). It also means that her parents think she is away when they decide to sell the house (pp. 100-1), which reinforces how remote they are from her (p.52).

The separateness of the Chippy school from the rest of the neighbourhood reiterates the implication that school education in itself is not valued in the Chippy community, despite it seemingly being a means of escape. (pp.140, 14). The physical features of the school also provide the means by which Zoe can be hidden (p. 144) and ultimately - by her own wiles - escape (p.156). However, just as Jonas is using his school time to plan his escape (p.158), so too is the benefit Zoe gains from being at the Chippy school nothing to do with its official function. Once again, the implied fear is that school will become a place whose designated function is useless for young people.

3. 'Confidante, mentor and friend' [?]': Representations of teachers in futuristic texts.

Because teachers in futuristic texts are often portrayed as being artificial and controlling, they are usually constructed as beings who should be treated with extreme caution by the reader. This contrasts with the underlying ideology of the texts, which tends to be towards stepping forward into the unknown with hope and courage (Dobson, p.187, Swindells, p.109, Lowry, p.179) and which advocates rebellion against controlling authority structures (Westall, pp.210-11).

The Headmaster in Futuretrack 5 is constructed as someone who ultimately is to be pitied rather than feared, being perceived by Kitson as 'an old actor in some clapped-out play who's forgotten his lines' (p.32). The rest of the staff, with the exception of Major Arnold*, are presented as merely part of the artificial environment: watching from the safety of the staffroom as the students find their results, and then submitting to the expected bonhomie (pp.16, 25).

In Daz 4 Zoe, Subby teachers are given very bad press. Zoe includes them in the list of people to whom she could go to talk about a problem, but feels that their answers would be totally predictable and therefore useless (p.31). Her own teacher, Miss Moncrieff, is given a larger role but her main function in the text is to enable the reader to 
learn the political cause of the gulf between Subbies and Chippies (pp.41-2). And with her 'smile ... like a shark' and 'gorgon special' look (p.42), as well as her treatment of Zoe (pp.42,48,49), it is hard for the reader to feel any sympathy towards either Miss Moncrieff or the ideas she attempts to teach

Daz's teacher, Mr James, by contrast, has his uses. Not only has he been the means by which Daz learns the story of the Minotaur and is thereby able to find his way through the tunnel to Zoe and then to return home (p.56), it is also Mr James to whom Daz goes in order to save Zoe, and $\mathrm{Mr}$ James through whom Zoe finds out about her grandmother and FAIR (pp.134, 151-2).

However, all the power does not rest with this particular teacher. He has to be manipulated by Daz into helping Zoe (pp. 134-5), and ultimately she escapes without James' knowledge (p.156). Teachers may therefore occasionally be of assistance to young people, but the texts suggest that the ultimate responsibility lies with the teenage protagonists and that teachers are at best a means to an end.

Despite having only a cameo role in The Giver, the Instructor also typifies the attitude of his society. Smiling and pleasant, he displays no strong emotion and is more interested in semantics than in developing responsibility in his students, for example, or even time management skills, which Asher's misdemeanour might also have raised (pp.3,4). His very title of Instructor (p.3) suggests that his main function is to tell people what to do, as opposed to encouraging them to think for themselves. Certainly, it must be conceded that not all teachers either in literature or in the wider world actually encourage independent thought (Lowry's Miss Moncrieff, for example, clearly does not [p.48]) but it is interesting to note the difference in etymology between the words 'instruct' and 'teach'. According to the dictionary, 'instruct' comes from the Latin word meaning 'to pile up' and 'teach' from the German and Greek words for 'show'. 'Piling up' is a much more invasive activity to do to someone than is showing that person something. Significantly, those who work at 'educating' the young are also called 'instructors' in The Inheritors (p.19).

In addition, the protagonists in The Inheritors also have counsellors to make sure that they do not oppose the Ideology of the Dome. Claudia's counsellor Kate may be 'patient' and 'good-natured' but Claudia knows full well that Kate is more interested in getting Claudia to support the Dome's Ideology than she is in any personal development for Claudia (pp.78-9). Once again young people in the texts are expected to support an education system whose chief aim is the continuation of a dysfunctional society.

\section{4. '[I]t was just words, right?": the emptiness of language}

Even though the representations of teachers vary among the texts, one consistent theme is the importance of language in schooling. Frequently, there is the suggestion that in futuristic societies it is believed that using the 'correct' form of words will automatically produce conformity with the society's beliefs. However, readers are positioned to see that this obsession on the part of teachers with what they perceive as 'correct' language actually blinds them to what is really going on in their society. It can also blind them to what is happening in the young protagonist whom they seek to help or indoctrinate.

In The Inheritors, for example, Claudia and the other young people are forced to read accounts of life in their past but the language used in these accounts has been carefully chosen to suggest that life (which is of course, contemporary life for the reader) in the late twentieth/ early twenty first century was terrible (pp.63-4). The language suggests so heavy a bias that readers cannot help but question what is being said.

What is actually going on underneath the language is given a similar twist even in the opening pages. With such bald and inflexible statements as 'The City is a model society' (p.4), readers are positioned to suspect an attempt at indoctrination. Therefore when readers see that the student is told to discuss these concepts thoroughly with [a] counsellor and gain a correct understanding', it can also be seen that thorough discussion and gaining understanding equals toeing the Party line (p.5). The rest of the text demonstrates that this is precisely the case (p.128, for example).

In $D a z 4 Z o e$, the potential slippage between truth and 
language becomes very clear in the interchange between Miss Moncrieff and Zoe. An astute reader can see that the scenario which Miss Moncrieff explains to Zoe could equally be represented through other language: namely that the Franchise (Income Qualification) Bill of 2004 was a means of disempowering the poor. Similarly, Zoe realises how great the gulf can be between language and meaning when she decides to adopt Galileo's policy of saying what people wanted to hear so that they wouldn't destroy him (p.55). Again, the reader is encouraged to see that language can be used to hide truth rather than to express it.

In The Giver, this gap between language and truth also helps Jonas to realise one of the fallacies on which his community is built. " $T$ The reason for precision of language was to ensure that unintentional lies were never uttered' Jonas muses (p.71) - but this assumes that by controlling language a person can also control truth. The rest of the text, however, demonstrates the inaccuracy of this assumption, for many of the greatest truths for Jonas are in fact beyond words - his first experience of sunburn (p.86), when he realises the beauty of a red apple (p.95), when he learns that he has the power to transmit memories (p.117), and the profound depth of his feelings for Asher and Fiona which cannot be smoothed away with words (p.132). That is not to say that words are not important, for it is partly through words that the memories which the text presents as being so important are shared. But the words are only a means to an end: what is emphasised is the importance of the feelings, rather than the words used to express them (p.154).

5. " $|A|$ lot of what they teach us in school is brainwashing too" ${ }^{10}$ : Alternative views to school.

Another consistent trend in the texts is that where there is what the reader is positioned to see as overt brainwashing on the part of the school or the teacher, there is almost invariably another character to offer an alternative view, both for the protagonist and for the reader. For Jonas, it is The Giver who helps him to understand the choices which their people made to bring the community to where it is in the text, and who helps him to see the negative side of their community (p.95, for example). In Swindells' text it is Zoe's grandmother who dares to challenge the prevailing Subby philosophy (p.44) and for Claudia, it is Mrs Winston who helps her to see both the positive side of pre-Armageddon life, and that it may in fact be possible to live outside the Dome (pp.125, 179).

However, as Claudia herself realizes, simply to invert an ideology does not free a person from it (p.97), and the information that the protagonists receive from these characters who offer an alternate view necessitates a great deal of soul searching before the protagonist chooses to act. And that action is always a significant risk, unlike the 'security' offered by indoctrination. Lieutenant Pohlman, for example, tells Zoe that she is 'safe in Silverdale' (p.84) whereas Zoe's grandmother tells her. 'I wish there was some way I could make all of this easier for you ... but there isn't' (p.106). Zoe, also, risks her life to leave Silverdale, and even though she has been influenced by her grandmother, when the crunch comes it is her own decision to leave (p.106).

Jonas, also, decides to leave his community but it is in order to restore the memories which his community needs. However, he ends up leaving without The Giver's help, and must rely purely on his own resources in order to save Gabriel's life (p.163). Similarly, by contrast with the dogma of the Ideology in The Inheritors Mrs Winston makes it clear that she is not absolutely certain that life is possible on the outside (p.179), and the reader is thereby positioned to feel that Claudia's decision to leave the Dome is her own (p.158).

6. 'A bleak, joyless world"1: How schooling in the future comments on the reader's present.

By taking to extremes traits of the reader's world, the text positions readers to examine those traits and also to think more deeply about how the horrors presented by the futuristic school and the society from which it has grown can be prevented. Futuretrack 5 and $D a z 4$ Zoe both warn against the increasing stratification of society, reflected in the excessive control in the middie class schools (Miss Moncrieff, in Daz 4 Zoe for example) as well as the clear delineation between the types of student in Westall's text especially (pp.8-9). The rigid structure which maintains a barrier between the Subbies and Chippies in Daz 4 Zoe (p.84) and those on either side of the Wire in Futuretrack 5 (p.17) also suggests the fear of which McGregor writes 
(p.33). In Westall's text, there is also the implied criticism of a dependence on technology without a corresponding focus on morality and emotion, reflected in the scene in which Kit expresses his feelings and Laura (the computer) responds with purely technical answers (p.52).

Of the four texts, Futuretrack 5 has the least positive ending, but there is a sense that even though Kit may be a physical prisoner he has at least moral freedom because he has been prepared to risk his life to program some sort of ethics into Laura (pp.245-6). This is prefigured in the school scenes, reflected in Kit's ironic jest: 'Triumph of man over microchip!' when the robot ships do not work (p.12). Significantly, some of the few references to contemporary life for the reader are in the scenes at Kitson's school, but they exist only for Kitson and the reader. Kit thinks 'But it's not healthy talking about thirty years ago' (the implied reader's present) and the question is: why? Was it so bad or - more likely, given the description of the Chinese mess waiter - so much better than life in the novel? By the end of the first page the reader has been positioned to feel that life in the time in which the novel is set is much less pleasant than in the reader's own, so much less pleasant that people are afraid to think of the past (p.7). In doing this, Westall is also inviting his readers to think about what is good about contemporary society and what needs to be preserved, as well as what needs to be watched. For example, the obsession with a tradition which Kitson points out is only thirty years old (p.20) - an obsession which hides great cruelty underneath (p. 11 , for example) - warns the reader to make careful choices about what is valuable. ${ }^{12}$

Given the community's fear of memories that go further back than the previous generation (p.93), it is not surprising that society contemporary for the reader is also scarcely mentioned in The Giver. ${ }^{13}$ Nonetheless, the emphasis on control of science at the expense of experiencing emotion, the clear delineation between groups in society, the dislike of the past, and the rigid control by the authorities which suggest fear (pp.113,52, 103,95) could all be seen to have grown from the traits in modern life for the reader which the social commentators quoted earlier have outlined.

In The Inheritors, phrases such as, 'There was little sense of cohesion or solidarity in twentieth-century society' (p.66) are presented with no explanation, and it is easy for readers to see how Claudia has come to the conclusion that life before the nuclear holocaust in 2016 was 'a vast anarchy in which individuals struggled for personal survival against a backdrop of escalating global disintegration and chaos' (p.67). Because there is no explanation or acknowledgment of the positive aspects of the reader's present, a person reading the text is thereby encouraged to think about what s/he actually does see as the real situation in contemporary life.

Underpinning the whole text, of course, is also the implied criticism of a society which could allow a nuclear holocaust to happen at all - accident or no accident (p.2). The fact that some of the younger members of the Dome are starting to see the nuclear disaster as a means by which the Party 'saved' the world shows the damage of indoctrination (p.67) in two ways: firstly that it discourages the sort of courage and independent thought which the reader is positioned to see as desirable (pp.186-7), and secondly that it can make a person see an horrific situation as positive. Because the position taken in this and the other texts is so extreme, the reader is encouraged to analyse both contemporary society in terms of the novel and the reader's own' world, and thereby form an independent conclusion. In addition, despite the thirteen years which have passed since the publication of Dobson's text, the nuclear threat has not completely abated as Gay Alcorn's recent newspaper article demonstrates (2001, p.5), so the actual threat of The Armageddon of Dobson's text - as well as its results - are still possibilities for the reader. Interestingly, Alcom situates the theoretical nuclear disaster in her article as occurring only a year before Dobson locates hers (p.2).

Despite the differences between the four texts, there is one significant similarity between the schools of the 1980s, early 1990s - and even 2001 - and the schools of a projected future: that their main aim is still socialisation. But whereas Mackay implies that in the early twenty-first century this is largely a positive experience (p.7), for the protagonists in Westall, Lowry, Dobson and Swindells' texts that socialisation comes at a great cost. Formal schooling in the four texts is presented as having very little relevance to the protagonist's personal development, 
for even though the young person may occasionally learn some useful information through formal education, the reader is usually positioned to see schools as at best irrelevant and at worst dangerous. If anything, young people in the texts succeed in spite of the school, not because of it. However by being places where aspects of contemporary life for the reader are presented, often with a great deal of bias, the reader is invited to analyse his/her own society and come to some conclusions about what is worth preserving in it and what dangers may eventuate because of it.

But whatever form the schooling takes, and whether it is constructed in the text as positive or negative, one overriding consistency emerges from all the novels: young people must take responsibility for their own lives and be prepared to take risks to find what truth means for them. And those truths are often profound and life changing, beyond school, society and, at times, even beyond language itself.

\section{NOTES}

1. Thornbury Darebin Secondary College Prospectus 2002, p.2.

2 Westall's text is set around the year 2010 (p.16), Swindells' some time after 2004 (implied on pp.41-2) Dobson's in 2046 (implied on pp.141-3). The capabilities of technology are implied in The Giver on p.95.

3. Even though these writers are focusing on Australia, the fact that the characteristics which they identify are also clearly discernible in texts by authors from other countries suggests that these traits may be common to Western developed nations.

4. The 'collective unconscious' is the level of the unconscious which Jung believed had 'contents and modes of behaviour that are more or less the same everywhere and in all individuals' (Jung 1972, p.4).

5. These aspects include music, memories and love (pp.179-80).

6. Swindells 1992, p.36.
7. Dobson, 1988, p.78.

8. Major Amold, by contrast, is adored by Kitson and his fellow students because he would 'give you the truth' (p.27). He is also given much more of a petsonality profile than is the Head (p.28, for example), and actually helps save Kit and Keri from the Paramils (pp.174-7). It is therefore much easier for the reader to feel sympathetic towards him, but the ineffectual nature of school is emphasised again when Kit thinks 'It wasn't exactly like getting into a muddle with your history essay' (p.170). Sure enough, he disappears from the text after this point.

9. Swindells 1992, p.55.

10. Swindells 1992, p.44.

11. Dobson 1988, p.67.

12. Black's article also supports this (1999, p.13).

13. One of the few allusions to it is when The Giver says to Jonas, 'People felt things once.' (p.154).

\section{REFERENCES}

Alcorn, Gay (2001)'President Bush goes ballistic' in The Age May 5.

Black, Rufus (1999) 'Age of meaninglessness' in The Age June 28.

Chambers (1972) Twentieth Century Dictionary. Edinburgh, W \& R Chambers.

Dobson, Jill (1988) The Inheritors. St Lucia, University of Queensland Press.

Jung, C. G. [1959] (1972) Four Archetypes. London, Ark.

Lowry, Lois (1993) The Giver. Boston, Houghton Mifflin Company.

McGregor, Craig (1995) 'Advance Australia where?' in The Age Good Weekend September 16.

Mackay, Hugh (2001), 'Why the young pine for life in the tribe' in The Age March 10. 
Manne, Robert (2000) 'Why modern Australia is two nations' in The Age June 26.

Merson, John (1999) 'That's four giant leaps for mankind' in The Age Good Weekend, November 27.

Stephens, John, '1992a, Language and Ideology in Children's Fiction. Longman, London.

Stephens, John, 1992b, 'Post-Disaster fiction: The problematics of a genre' in Papers: Explorations into Children's Literature 3, 3.

Swindells, Robert [1990] (1992) Daz 4 Zoe. London, Penguin.

Thombury Daredin Secondary College, 2002 Prospectus

Westall, Robert [1983] (1985) Futuretrack 5. Harmondsworth, Penguin.

\section{BIOGRAPHICAL NOTE}

Elizabeth Braithwaite is a writer with The Council for Christian Education in Schools (Victoria). Her interest in children's literature spans many years. She also enjoys music and cycling. 